MATEC Web of Conferences 25, 04013 (2015)

DOI: $10.1051 /$ matecconf/ 20152504013

(C) Owned by the authors, published by EDP Sciences, 2015

\title{
Study on the Influences of Coastline Changes in Hydrodynamic Force and Tidal Prism of Tianjin Offshore Area
}

\author{
Honglingyao Chen \& Hongtao Yuan \\ Tianjin Research Institute for Water Transport Engineering, M.O.T., Tianjin, China
}

\begin{abstract}
Numerical simulation of Tianjin coastal waters tidal field by using the Mike21 numerical model. The impact of coastline changes in hydrodynamic force and tidal prism of Tianjin offshore area was predicted. Results show that after the change of coastline, there is no obvious change on the form of flow field at each typical moment for sea areas. But the tidal dynamic condition in most of sea area is weakened to some extent, the most obvious change exists in the flow field of the alongshore reclamation engineering areas. The coastline change is caused by sea filling and, the land accretion directly causes the decrease in the area of Tianjin nearshore waters, so as to decrease the tidal prism.
\end{abstract}

Keywords: Tianjin offshore area; coastline changes; hydrodynamic; tidal prism

\section{INTRODUCTION}

In recent years, a series of tideland reclamation projects in coastal zone have been implemented to meet the demand of economic development in Tianjin. With the acceleration of the development and reclamation of Tianjin offshore area, the ratio of the natural coastline within the sea area is declining. In northern Port of Tianjin, there is new TEDA land reclamation; meanwhile, new port areas of north section and the east and south sections have been built near the Port of Tianjin area. In southern Port of Tianjin, the supporting Lingang Industrial Zone and Lingang Industrial Area have been built. Land reclamation is mainly used for the development of Port of Tianjin and the construction of Lingang Industrial Area, which substantially transforms the natural coastline and tidal flat wetland into artificial coastline and land. By 2009, the length of the natural coastline has been $98.02 \mathrm{~km}$, only accounting for $37.08 \%$ of coastline ratio. The total length of the coastline has been decreased to some extent, which mainly attributes to the further sea reclamation in the Lingang Industrial Area, and part of artificial coastlines are changed from curve as straight line. Therefore, the total length of the coastline is decreased by $1.61 \mathrm{~km}$, but more coastlines are changed as artificial coastline. And up to 2010, the length of natural coastline has been 68.49 , only accounting for $26.05 \%$ of the coastline ratio, but the length of the artificial coastline has been increased to $194.41 \mathrm{~km}^{[1]}$ In this paper, the change information of the coastline caused by development activities in coastal zone from 2004 to 2010 is used to analyze the influence of coastline changes in hydrodynamic force and tidal prism ${ }^{[2}$ ${ }^{3]}$ of Tianjin offshore area via a numerical simulation method.

\section{MODEL BUILDING AND VALIDATION}

\subsection{Model control equation}

The governing equation of the MIKE2 $21^{[4]}$ two dimensional hydrodynamics module includes 1 continuity equation and 2 momentum equations:

The continuity equation is as follows:

$\frac{\partial \zeta}{\partial t}+\frac{\partial p}{\partial x}+\frac{\partial q}{\partial y}=\frac{\partial d}{\partial t}$

The $X$-axial momentum equation is as follows:

$\frac{\partial p}{\partial \mathrm{t}}+\frac{\partial}{\partial x}\left(\frac{p^{2}}{h}\right)+\frac{\partial}{\partial y}\left(\frac{p q}{h}\right)+g h \frac{\partial \zeta}{\partial x}+\frac{g p \sqrt{p^{2}+q^{2}}}{C^{2} h^{2}}$ $-\frac{1}{\rho_{w}}\left[\frac{\partial}{\partial x}\left(h \tau_{x x}\right)+\frac{\partial}{\partial y}\left(h \tau_{x y}\right)\right]-\Omega q-f V V_{X}+\frac{h}{\rho_{w}} \frac{\partial}{\partial x}\left(p_{a}\right)=0$

The $Y$-axial momentum equation is as follows:

$\frac{\partial p}{\partial \mathrm{t}}+\frac{\partial}{\partial y}\left(\frac{p^{2}}{h}\right)+\frac{\partial}{\partial x}\left(\frac{p q}{h}\right)+g h \frac{\partial \zeta}{\partial y}+\frac{g p \sqrt{p^{2}+q^{2}}}{C^{2} h^{2}}$ $-\frac{1}{\rho_{w}}\left[\frac{\partial}{\partial y}\left(h \tau_{x x}\right)+\frac{\partial}{\partial x}\left(h \tau_{x y}\right)\right]-\Omega q-f V V_{y}+\frac{h}{\rho_{w}} \frac{\partial}{\partial y}\left(p_{a}\right)=0$

In the formula, $\zeta$ is tide level, namely the distance from horizontal plane to a certain base level; $h$ is depth of water; $p$ and $q$ are respectively the vertical average flow rate components on $\mathrm{x}$ and $\mathrm{y}$ axis; $u$ and $v$ are respectively the mean depth flow rate on $\mathrm{x}$ and $\mathrm{y}$ axis; $\tau_{x x}, \tau_{x y}$ and $\tau_{y y}$ are respectively the components of the shear stress in each direction; $\Omega$ is Coriolis Force diameter $=2 \cdot \omega \cdot \sin \psi ; \mathrm{g}$ is acceleration of gravity; $\mathrm{C}$ is Chezy coefficient; $\rho_{\mathrm{w}}$ is the density of water; $f$ is the wind friction factor; $f=\gamma \alpha^{2} \cdot \rho_{\alpha}, \gamma \alpha^{2}$ is the wind stress coefficient; $\rho_{\alpha}$ is the air density; $V, V_{x}$ and $V_{y}$ are respectively the components of wind speed on $\mathrm{x}$ and $\mathrm{y}$

This is an Open Access article distributed under the terms of the Creative Commons Attribution License 4.0, which permits unrestricted use, distribution, and reproduction in any medium, provided the original work is properly cited. 


\section{MATEC Web of Conferences}

axis; $\mathrm{x}$ and $\mathrm{y}$ are rectangular coordinates, and $\mathrm{t}$ is time.

\subsection{Boundary conditions}

Lateral boundary conditions: The normal component constant of flow is zero at the fixed boundary; $V(x, y, z, t)=0$ and there is no heat and salt exchange.

Open boundary conditions: The border of small zone was outlined by framing a large zone. The coordinates of simulated large zone are ranged from $117^{\circ} 32^{\prime} 25^{\prime \prime} \mathrm{E}$ to $122^{\circ} 17^{\prime} 3^{\prime \prime} \mathrm{E}$ and from $37^{\circ} 6^{\prime} 1^{\prime \prime} \mathrm{N}$ to $40^{\circ} 58^{\prime} 10^{\prime \prime} \mathrm{N}$. The open boundary in open sea of the large zone was determined with tidal level hydrograph $Z=Z(T)$ which was provided in China Tide Table and debugged on the basis of measured hydrological data. The boundary of small zone was determined by the calculation results of upper level model and the coordinates of simulated small zone which are ranged from $117^{\circ} 32^{\prime} 2^{\prime \prime} \mathrm{E}$ to $118^{\circ} 8^{\prime} \mathrm{E}$ and from $38^{\circ} 32^{\prime} \mathrm{N}$ to $39^{\circ} 13^{\prime} 12^{\prime \prime} \mathrm{N}$.

\subsection{Scope of calculation and grid settings}

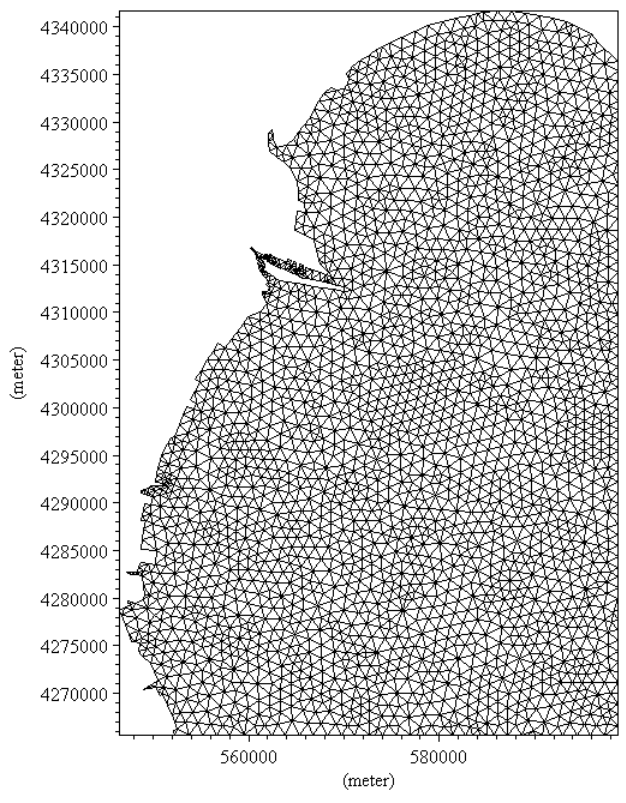

Figure 1. Model range and computational grid

The area of Tianjin sea area is about $3,000 \mathrm{~km}^{2}$, in which, the sea area with depth which is 0 to $-5 \mathrm{~m}$ is about $847 \mathrm{~km}^{2}$, and the section with depth which is -5 to $-15 \mathrm{~m}$ is about $746 \mathrm{~km}^{2}$, the area of intertidal zone is about $336 \mathrm{~km}^{2}$. The Tianjin coastline starts from the point of interaction between the north boundary of the Hebei District administrative region and Tianjin, and the coastline (about $2.4 \mathrm{~km}$ to the west of Jianhe port) is to the north and to Qikou to the south. The calculation range of the Tianjin offshore area is the region surrounded by coastline, namely, $118^{\circ} 8^{\prime} \mathrm{E}$ longitude and $38^{\circ} 32^{\prime} \mathrm{N}$ latitude line, the south-north distance is about $71 \mathrm{~km}$, and it is $47 \mathrm{~km}$ between east and south. In the aggregate, there were 2,696 triangle grid nodes and 5,009 triangular elements in the simulated area. Figure 1 shows the boundary of model and grids used for calculations.

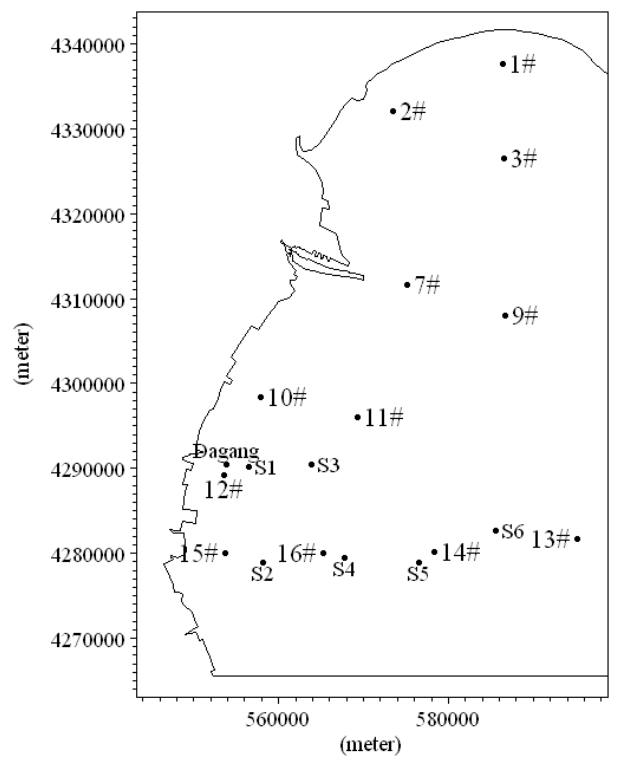

Figure 2. Verification point location

\subsection{Verification and analysis of simulation results}

The field data of spring and neap tides measured in July, 2008 were used as input to verify tide level, velocity and flow direction. In total, 6 tide stations (S1 S6) and one tidal level stations (Dagang) were established. Figure 2 shows the positions of verification points. Figures $3-5$ show verification curves of measured values and calculated values of tidal level, current velocity and direction. It is indicated on the observation curves that there is only a slight difference between the measured values and calculations for each station in consideration of their overall trends. The calculated tidal level variation and the velocity and flow direction of each layer are basically identical to the experimental data, which indicates that the motion of tide simulated with the model can basically reflect the water flow conditions in Tianjin sea area and thus can be used as the basis for further analysis and calculation.

\section{INFLUENCES OF COASTLINE CHANGE ON HYDRODYNAMIC FORCE}

Based on the figure of tide-field at flux and reflux moments of Tianjin sea area, it can be seen that the tide in this sea area has the reversing current property, and the current basically makes shoreward and off- 


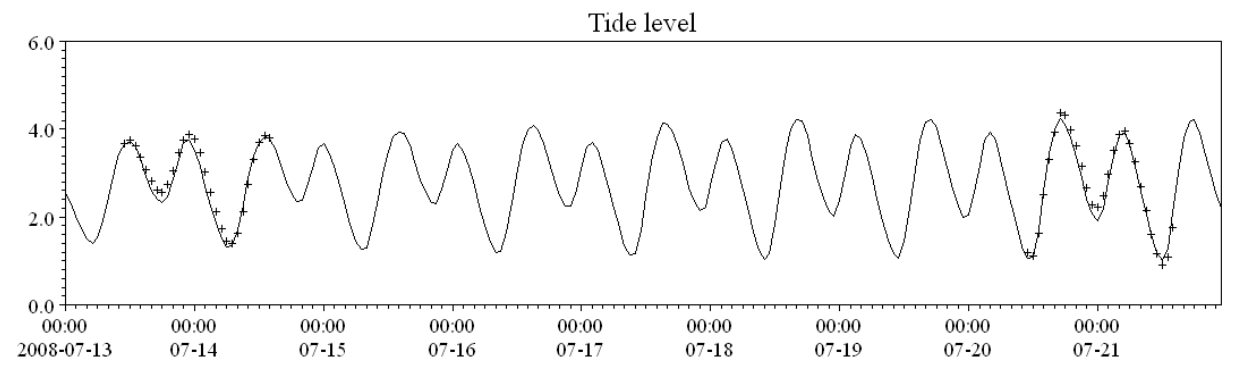

Figure 3. Comparison of predicted (-) and measured $(+)$ tide level at Dagang tidal station
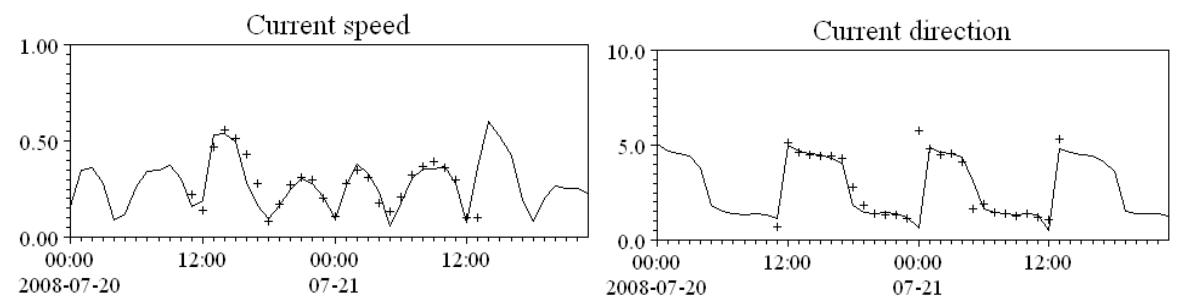

Figure 4. Spring tide predicted (-) and measured (+) flow velocity and flow direction validation at S3 station
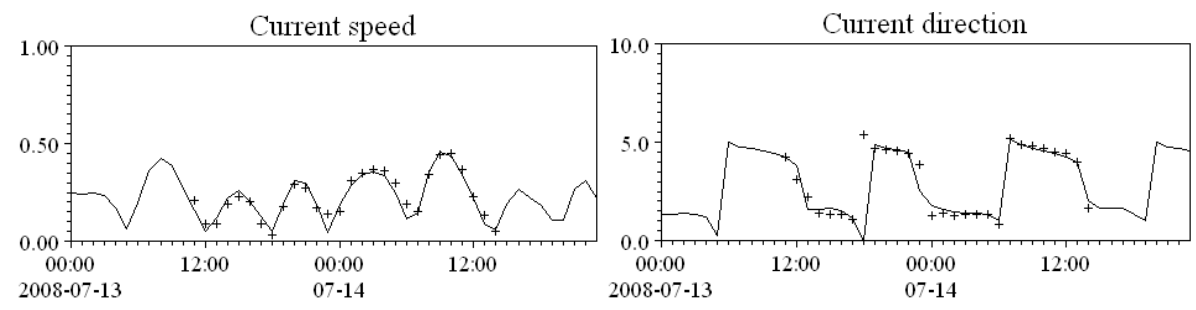

Figure 5. Neap tide predicted (-) and measured (+) flow velocity and flow direction validation at S5 station

shore movements outward. After the completion of the reclamation works, there is no obvious change to the form of flow field in each typical moment. Due to the influence of the offshore port structures, the current flows along with the coast or the edge of the structures, and for the sea area near the project rejoin, there are different degrees of change on flow velocity and flow direction due to the changes of partial coastlines.

The distribution diagram of the flow velocity at flux and reflux moments of Tianjin offshore area before and after coastline change is drawn based on the analogue tide field in the Tianjin offshore area before and after the coastline change. It can be seen from aforementioned figure that the flood strength is more than strength of ebb, and the flow velocity is gradually increased from coast to deep water. The tidal dynamic condition in most region of the sea area is weakened to some extent after the coastline changes, and its influence is reduced with the increase of the offshore distance. The most obvious change exists in the flow field of the alongshore reclamation engineering areas, and there is a large velocity change to the flow rate of its surrounding waters.

In order to specify the influence of coastline change on the flow field of Tianjin offshore area more clearly, we extract 12 representative points whose positions are shown in Figure 2 to compare and analyze the tide flow rate and direction of the representative points at flood tide and ebb tide moments for spring and neap tides. It reflects the change situations of the flow rate, tide level and other hydrologic features caused by coastline changes on this account. Study shows that there is different degree of change in the flow rate and direction for each representative point before and after the coastline change, which explains relatively obvious response change of the fluid and flow pattern existing on the shore configurations. After the change of coastline, the maximum amplitude on flow rate is up to $76.5 \%$, the relative variation of change of the flow rate during flood is $2.0 \%-67.3 \%$, and it is $4.5 \%-76.5 \%$ during ebb tide. There is relatively less change on the flow direction of each representative point, only the flow direction of 12\# position near Nangang Industrial Zone has relatively obvious change, and the range of 


\section{MATEC Web of Conferences}

relative change is $0.7 \%-30.2 \%$. From 2004 to 2010 , the land reclamation is mainly near the Port of Tianjin, the change of the coastline makes representative points 7\#, 9\# and 12\# near the Port of Tianjin have relatively sharp velocity changes, and there is less change on the representative points which are far away from the alongshore reclamation works. It is because the construction of the reclamation works partially increases the resistance of the ocean current, so as to cause obvious reduction of the flow rate in Tianjin coastal sea area after the change of coastline.

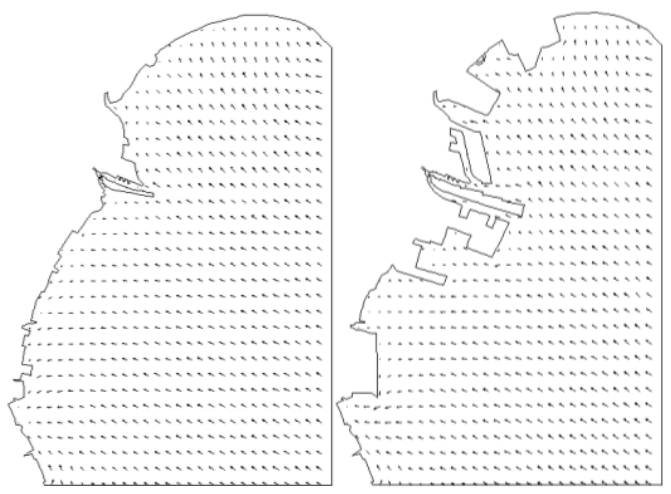

Figure 6. Tide field at flood strength of situations before and after the coastline changes

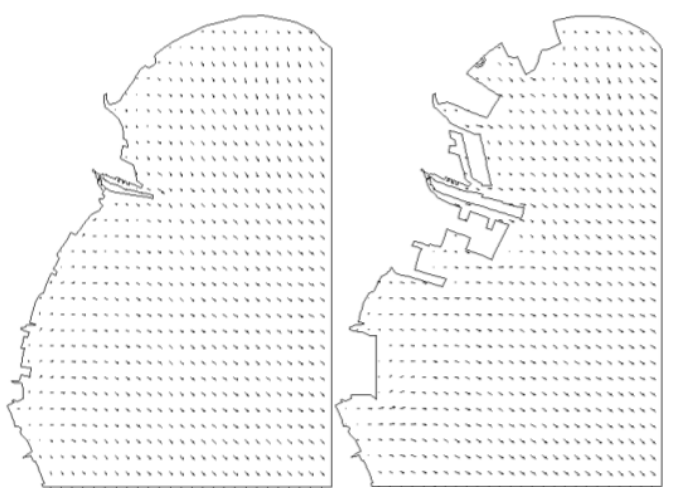

Figure 7. Tide field at ebb strength of situations before and after the coastline changes

\section{INFLUENCES OF COASTLINE CHANGE ON TIDAL PRISM}

Tidal prism is the volume dose of the tide water which is capable of being received by a bay; it is an important index to represent the hydrodynamic force, water quality and biochemical circumstance of the bay, especially for the semi-closed bay. Its value directly affects the water exchange capacity of the bay and the relocation diffusion of the pollutants, and constrains the self-cleaning capacity and environment capacity of the bay consequently. Therefore, it is relatively im- portant to maintain a good ecological environment The volume that the bay receives the tide water is the tidal prism; the volume difference of the admissible seawater in the bay is obtained by calculating the area of each grid in the Bohai Bay and the high-low tide waterhead of the grid point, so as to calculate the tidal prism of the Bohai Bay. The computational formula is as follows ${ }^{[5]}$ :

$\mathrm{P}=\mathrm{h} \mathrm{S}$
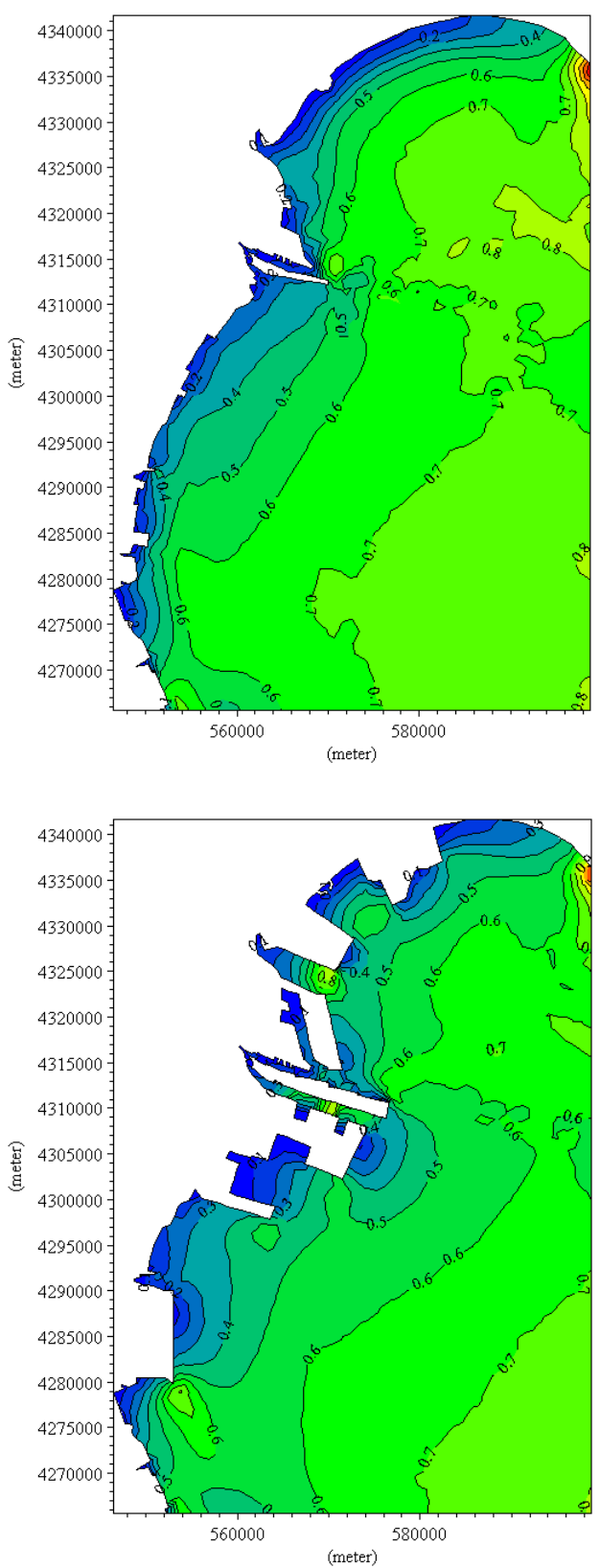

Figure 8. Distribution diagram of the flow velocity at flux moments before and after the coastline changes 

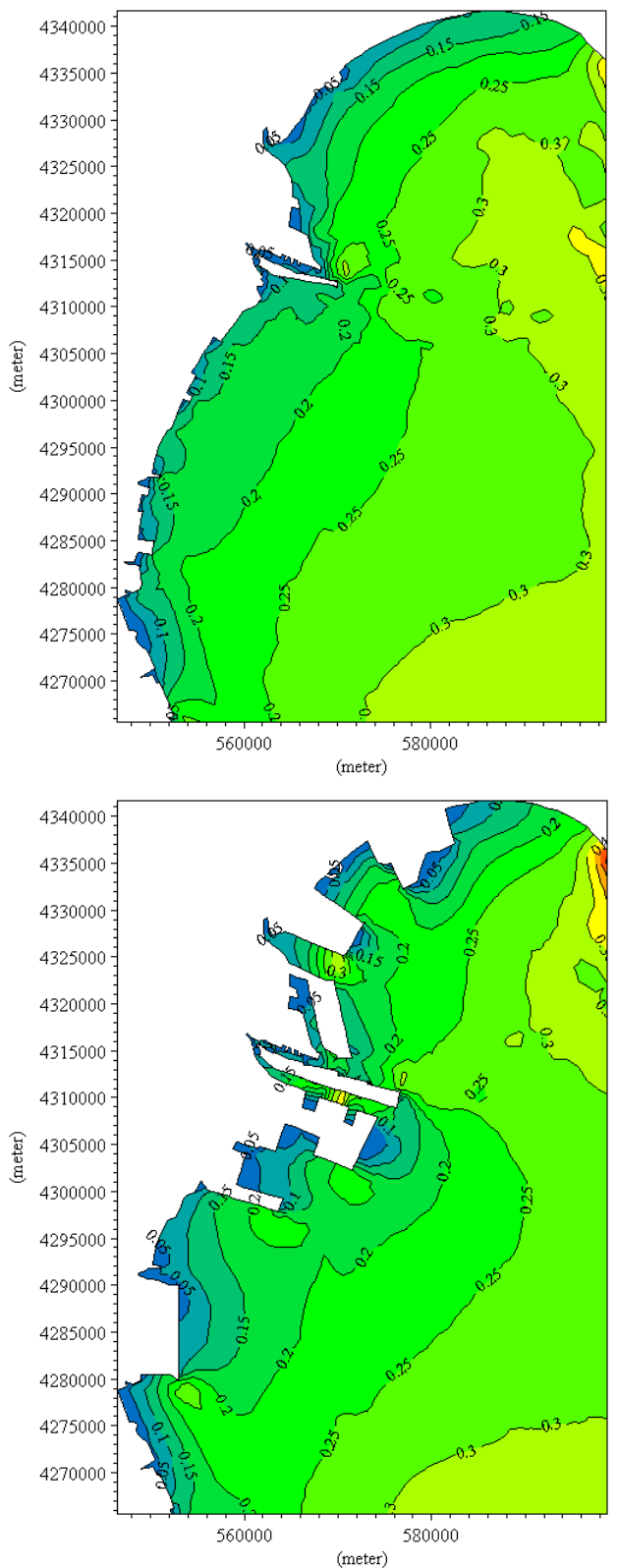

Figure 9. Distribution diagram of the flow velocity at reflux moments before and after the coastline changes

Where $\mathrm{P}$ is the tidal prism under mean range condition, $\mathrm{h}$ is the mean range, $\mathrm{S}$ is the average water area (namely, the mean of the water areas in mean high tide and low tide)

It can be seen from the result of the tidal prism before and after the coastline change that the change of the coastline from 2004 to 2010 reduces $0.73 \times 10^{9} \mathrm{~m}^{3}$ of the tidal prism of the spring tide in Tianjin offshore area, its scale of decrease is $9.5 \%$. The tidal prism of the neap tide is decreased by $0.65 \times 10^{9} \mathrm{~m}^{3}$, and the ratio of decrease is $9.8 \%$. Therefore, it is observed that the coastline change has a certain influence on the change of tidal prism in Tianjin offshore area.

In order to analyze the response relationship between the coastline change and the tidal prism, the contrastive analysis on the changes of sea area and tidal prism will be implemented. The area of Tianjin offshore area can be calculated via the boundary selected from the mathematical model, the sea area is $3,000 \mathrm{~km}^{2}$ in 2004 , and it is $2,739 \mathrm{~km}^{2}$ in 2010 . The ratio of decrease is $8.7 \%$, and the reclamation area of Tianjin offshore area is up to $261 \mathrm{~km}^{2}$. The average tidal prism of the spring-neap tide is reduced by $0.69 \times 10^{9} \mathrm{~m}^{3}$, and the ratio of decrease is $9.6 \%$. Therefore, it can be seen that the coastline change, sea area and tidal prism of the Tianjin offshore area are closely related. The decrease of tidal prism mainly attributes to the direct decrease of the sea area which is caused by sea reclamation works, and the decrease of the tidal prism means the decrease of the environment capacity in Tianjin offshore area, which reduces the capacity that contains water quality pollutant, and causes serious impact on the water quality environment of the sea area.

\section{CONCLUSION}

After the change of coastline, there is no obvious change on the form of flow field at each typical moment for sea areas. Due to the influence of the port structures in offshore, the current flows along with the coast or the edge of the structures, and for the sea area near to the project rejoin, there are different degrees of change in flow velocity and flow direction due to the changes of partial coastlines.

After the coastline changes, the tidal dynamic condition in most of sea area is weakened to some extent, and its influence degree is reduced with the increase of the offshore distance. The most obvious change exists in the flow field of the alongshore reclamation engineering areas, and there is a large velocity change to the flow rate of its surrounding waters.

The coastline change, sea area and tidal prism of the Tianjin offshore area are closely related. Sea area is decreased by $261 \mathrm{~km}^{2}$, and the ratio of decrease is $8.7 \%$. The average tidal prism of the spring-neap tide is reduced by $0.69 \times 10^{9} \mathrm{~m}^{3}$, and the ratio of decrease is $9.6 \%$. The coastline change which is caused by sea filling and land accretion directly causes the decrease in the area of Tianjin nearshore waters, so as to cause the decrease of tidal prism and the weakening of seawater self-cleaning capacity, and aggravate the pollution in Tianjin offshore area.

\section{REFERENCES}

[1] W Q Meng, X M Wang, H Y Li, \& X Ding. 2012. Ecological impacts of marine reclamation in Binhai New Area of Tianjin. Marine Environmental Science, 31(1) 83-87. 


\section{MATEC Web of Conferences}

[2] X C Wang, C Q Sun, Y L Sun, \& A G Lou. 2000. Study on impact of Jiaozhou Bay sea-filling on hydrodynamic environment. Marine Environmental Science, 19(3): 56-59.

[3] Park JW, \& Park SS. 1998. Hydrodynamic modeling of tidal changes due to land reclamation in an open-ended harbor, Pusan, Korea. Journal of Environmental Science and Health Part a-Toxic/Hazardous Substances \& Environmental Engineering, 33(5): 877-890.

[4] DHI.MIKE21\&MIKE3 Flow Model FM Hydrodynamic and Transport Module Scientific Documentation. Denmark: DHI Water \& Environment, 2009.

[5] M Liu, X H Xi, \& L Y Lei. 2013. The effects of coastal reclamation on hydrodynamics in Jinzhou Bay. Journal of Dalian Ocean University, 28(1): 110-114. 